\title{
Correction to: Effect of Lycium barbarum polysaccharide supplementation in non- alcoholic fatty liver disease patients: study protocol for a randomized controlled trial
}

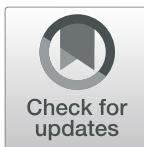

Lu-Lu Gao ${ }^{1,2}$, Yu-Xiang Li ${ }^{3}$, Jia-Min Ma², Yi-Qiong Guo ${ }^{2}$, Lin Li ${ }^{4}$, Qing-Han Gao ${ }^{2}$, Yan-Na Fan², Meng-Wei Zhang ${ }^{2}$, Xiu-Juan $\mathrm{TaO}^{2}$, Jian-Qiang $\mathrm{Yu}^{5^{*}}$ and Jian-Jun Yang ${ }^{2^{*}}$

Correction to: Trials 22, 566 (2021)

https://doi.org/10.1186/s13063-021-05529-6

Following the publication of the original article [1], we were notified that the first affiliation of the first author was incorrect.

- Originally published affiliation: School of Nursin, Shandong First Medical University (Shandong Academy of Medical Sciences), Jinan 250000, Shandong, China

- Corrected affiliation: School of Public Health, Xinxiang Medical University, Xinxiang 453003, Henan, China

The original article has been corrected.

\section{Author details}

'School of Public Health, Xinxiang Medical University, Xinxiang 453003, Henan, China. ${ }^{2}$ School of Public Health and Management, Ningxia Medical University, 1160 Shengli Street, Yinchuan 750004, China. ${ }^{3}$ School of Nursing, Ningxia Medical University, 1160 Shengli Street, Yinchuan 750004, China. ${ }^{4}$ Physical Examination Center, People's Hospital of Ningxia Hui Autonomous Region, 301 Zhengyuan North Street, Yinchuan 750004, China. ${ }^{5}$ Department of Pharmacology, Pharmaceutical Institute of Ningxia Medical University, 1160 Shengli Street, Yinchuan 750004, China.
Published online: 30 September 2021

\section{Reference}

1. Gao, et al. Effect of Lycium barbarum polysaccharide supplementation in non-alcoholic fatty liver disease patients: study protocol for a randomized controlled trial. Trials. 2021;22:566. https://doi.org/10.1186/s13063-021-0552 $9-6$.

The original article can be found online at https://doi.org/10.1186/s13063021-05529-6.

* Correspondence: yujq910315@163.com; Yangjianjun_1970@163.com

${ }^{5}$ Department of Pharmacology, Pharmaceutical Institute of Ningxia Medical University, 1160 Shengli Street, Yinchuan 750004, China

${ }^{2}$ School of Public Health and Management, Ningxia Medical University, 1160 Shengli Street, Yinchuan 750004, China

Full list of author information is available at the end of the article

(c) The Author(s). 2021 Open Access This article is licensed under a Creative Commons Attribution 4.0 International License, which permits use, sharing, adaptation, distribution and reproduction in any medium or format, as long as you give appropriate credit to the original author(s) and the source, provide a link to the Creative Commons licence, and indicate if changes were made. The images or other third party material in this article are included in the article's Creative Commons licence, unless indicated otherwise in a credit line to the material. If material is not included in the article's Creative Commons licence and your intended use is not permitted by statutory regulation or exceeds the permitted use, you will need to obtain permission directly from the copyright holder. To view a copy of this licence, visit http://creativecommons.org/licenses/by/4.0/ The Creative Commons Public Domain Dedication waiver (http://creativecommons.org/publicdomain/zero/1.0/) applies to the data made available in this article, unless otherwise stated in a credit line to the data. 